\title{
Rehabilitation of complex regional pain syndrome: evidence based or trial and error?
}
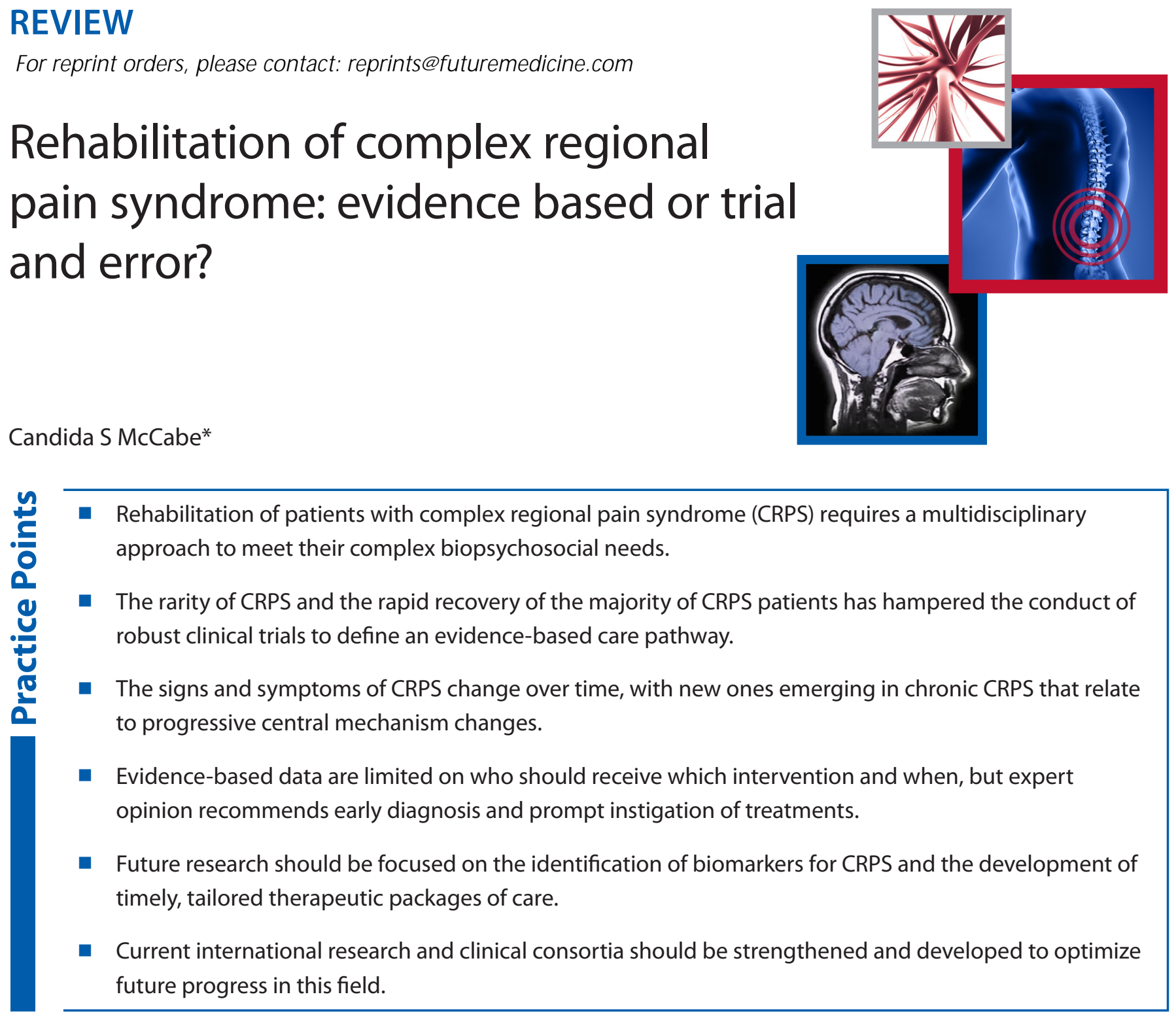

SUMMARY Complex regional pain syndrome (CRPS), a relatively rare condition, is commonly diagnosed late and has no known cause or cure. There is a limited evidence base for therapeutic interventions and the majority of patients make a spontaneous recovery. The florid signs and symptoms of early CRPS are diminished and altered in the more persistent treatment-resistant form. New signs and symptoms, not listed in diagnostic criteria, begin to emerge that can confuse both the patient and clinician, and lead to questioning of the diagnosis. Trying to implement timely and evidence-based rehabilitation techniques within the above scenario is a significant challenge. This article will discuss those challenges and consider recent clinical and research advances that have sought to address some of these problems in CRPS type I.

Rehabilitation aims to restore the physical and psychosocial deficits that may have been incurred due to injury or disease and, as such, commonly requires a multidisciplinary approach. For individuals with complex regional pain syndrome (CRPS), early diagnosis and prompt instigation

*Bath Centre for Pain Services, Royal National Hospital for Rheumatic Diseases, Bath, BA1 1RL, UK 
of rehabilitation is now widely recommended as the best way to achieve optimum patient outcomes [1-3]. This is clear, definitive guidance and intuitively feels correct; however, in clinical practice, CRPS is commonly underdiagnosed $[4,5]$. Patients describe a delay in diagnosis and a wide variety of interventions throughout a meandering pathway of care that may, or may not, result in a patient-perceived satisfactory outcome. This discrepancy between 'desired' and 'actual' care may arise due to a number of factors, including poor recognition of this relatively rare condition by healthcare professionals. However, even when CRPS is accurately diagnosed there is a lack of high-quality evidence to define the precise content, frequency and timing of a rehabilitation intervention after symptom onset.

The challenge of designing \& evaluating rehabilitation interventions in CRPS

In order to specify an accurate and effective intervention, it is important to know the cause and course of a condition. Unfortunately, neither of these are clear in CRPS; the exact cause of the condition is unknown and its trajectory varies between and within individuals with no definition of recovery to measure improvement against.

CRPS is acknowledged to be a multisystem syndrome that involves aberrant changes in vasomotor function, inflammatory mechanisms and cortical processing [6]. These changes are probably initially triggered by a peripheral insult that quickly evolves into a centrally driven condition for which there is currently no cure [6,7]. For the vast majority of patients, symptoms resolve in a matter of months and by 1 year, as many as $80-85 \%$ of patients may be asymptomatic, as recorded in a postfracture cohort [8]. However, the remaining $15-20 \%$ continue to experience disabling symptoms and are commonly left with long-term functional impairments, as well as the psychosocial impact of chronic pain [9-11]. This lack of clarity on the cause of the syndrome, and the natural rapid recovery from the condition for many patients, means that targets for rehabilitation in early CRPS are difficult to identify and evaluate in terms of efficacy or need. By the time the condition has lasted for more than 1 year and proven to be treatment resistant or chronic, the potential for interventions to provide significant health benefits is reduced, and therefore population sizes for clinical trials need to be large. In a relatively rare condition, especially in its persistent, chronic form (incidence rates range from 5.46 to 26.2 per 100,000 person years $[12,13])$, the recruitment of large patient cohorts can be a substantial challenge. The problem is further compounded by the daily, or even hourly, fluctuation in signs and symptoms that many patients experience. Identifying the impact of a therapeutic intervention against a constantly changing clinical picture means controlled trials are essential. Furthermore, the multisystem nature of CRPS means that multimodal therapies are likely to deliver the optimum outcome, but conducting such complex interventions are resource intensive and methodologically daunting [14].

Clearly the ideal solution would be to identify those at risk of CRPS prior to onset, or very early in the condition, and prevent the escalation of signs and symptoms; thereby negating the need for rehabilitation at all. Current research is precisely focused on this, with the aim of identifying prognostic markers for CRPS, ideally prior to surgical interventions or immediately post-trauma [6]. To date there is no evidence of psychological predictors [15]; however, de Mos and colleagues found a significant association between CRPS and a prior diagnosis of migraine or osteoporosis in a cohort of 186 people with CRPS [16]. Other identified risk factors include immobilization of the limb post fracture [16], complaint of a tight plaster cast [17] and current use of angiotensin-converting enzyme inhibitors [18]. No robust genetic associations have been identified to date, but there is evidence of CRPS occurring more commonly in some families, thereby suggesting that genetics may play a role [19]. Further work with larger study cohorts is required to determine to what degree genetics contribute to the development of CRPS.

In the absence of definitive prognostic indicators for CRPS, but with the recommendation of treating CRPS promptly to optimize outcome, early identification of the signs and symptoms is essential.

\section{Identifying the signs \& symptoms of early \& persistent CRPS to instigate rehabilitation}

Patients with CRPS are encountered within a diverse range of primary and secondary care settings [3], but are most commonly seen within orthopedic and pain clinics as the condition is usually triggered by trauma to a limb, most commonly a fracture [13]. Disturbances in sensory, 
motor and autonomic pathways are normally present in a single limb; although they may occur in multiple limbs and other body regions [20-22]. The degree to which these disturbances occur will vary between patients and fluctuate on a daily, or even hourly, basis within individuals. CRPS is defined as either CRPS type I or II depending on the presence (II) or absence (I) of identifiable nerve damage (Table 1) [23]. Similar therapeutic approaches are used for both types, although only type II meets the criteria for a neuropathic pain condition [24]. This article focuses on CRPS type I.

In the early stages, the patient commonly complains of severe burning pain and the limb is edematous, with the skin shiny and mottled in color (Figure 1). The affected limb may feel warm or cool to touch, and may be sweaty in appearance with either excessive or reduced hair and nail growth. The patient is extremely protective of the limb and is reluctant for any touch to it, including clothing or bed covers at night [25]. Movement of the limb is likely to be painful and there may also be evidence of tremor, reduced quality of movement and a delay in instigating movements $[25,26]$. Patients often have a strong dislike of the limb, reduced ownership and disturbances in perceived size and shape of the limb [27-29]. As well as these disturbances in body perception, the clinician may be able to elicit referred or double sensations when touching the limb, or the area adjacent to the limb, on the somatosensory cortex $[30,31]$. For example, touch to a CRPS left hand may evoke a perception of touch to the left side of the face, or touch to a CRPS foot evokes a similar sensation on the ipsilateral knee. Referred sensations can be a bidirectional phenomenon and are usually modality specific. Approximately one-third of patients with CRPS have been shown to exhibit referred sensations that are lost as the condition resolves [30]. These findings, and reports of body perception disturbances, are considered to be indicative of the neuroplastic changes known to occur in the somatosensory cortical maps in
CRPS and other chronic pain conditions $[32,33]$. Imaging data have demonstrated a reduction in the representation of the CRPS-affected body part on the primary sensory cortex and increased activity in the representational motor area [33,34]. A direct correlation has been demonstrated between the extent of cortical reorganization and the level of pain perceived in CRPS, with pain reducing as the changes on the somatotopic and somatosensory maps start to reverse $[35,36]$.

In its early form, the florid signs and symptoms of CRPS make it relatively easy to diagnose, but in its chronic form this becomes more problematic (Figure 2). Over time, the edema usually reduces, hair growth returns to a more normal pattern and color changes may be less apparent. However, the level of disability may increase due to a spread in the extent and intensity of allodynia, the negative impact on psychosocial function from living with chronic pain $[9,10]$ and a progression in motor problems [20]. The usually flexed postures of a CRPS dystonia occur in approximately $25 \%$ of all patients with a distal-to-proximal spread of limb contracture [37]. When dystonia is present, functional rehabilitation can be particularly challenging and may consequently indicate a poor outcome [38]. Muntts and colleagues have recently identified evidence of thermal hypesthesia (both hot and cold) in this dystonic patient group [39]; however, to date, the etiology behind these motor and sensory changes can only be postulated at, and appear to involve both peripheral and central mechanisms [26,39]. Whether evidence of thermal hypesthesia in the early stages of CRPS could be used as a prognostic marker for dystonia is not yet known, currently; quantitative sensory testing has not identified a unique CRPS pattern versus other neuropathic pain conditions [40]. However, there is evidence that those with CRPS have a reduced threshold to tactile stimulation, pressure and heat pain $[41,42]$.

Recent work by Cohen et al. has demonstrated clinical evidence of parietal dysfunction in those

\section{Table 1. Budapest diagnostic criteria ${ }^{\dagger}$.}

\begin{tabular}{|c|c|}
\hline Category & Sign/symptom \\
\hline Sensory & $\begin{array}{l}\text { Allodynia (pain to light touch and/or temperature sensation and/or deep somatic } \\
\text { pressure and/or joint movement) and/or hyperalgesia (to pin prick) }\end{array}$ \\
\hline Vasomotor & Temperature asymmetry and/or skin color changes and/or skin color asymmetry \\
\hline Sudomotor/edema & Edema and/or sweating changes and/or sweating asymmetry \\
\hline Motor/trophic & $\begin{array}{l}\text { Decreased range of movement and/or motor dysfunction (weakness, tremor, } \\
\text { dystonia) and/or trophic changes (hair, nail, skin) }\end{array}$ \\
\hline
\end{tabular}




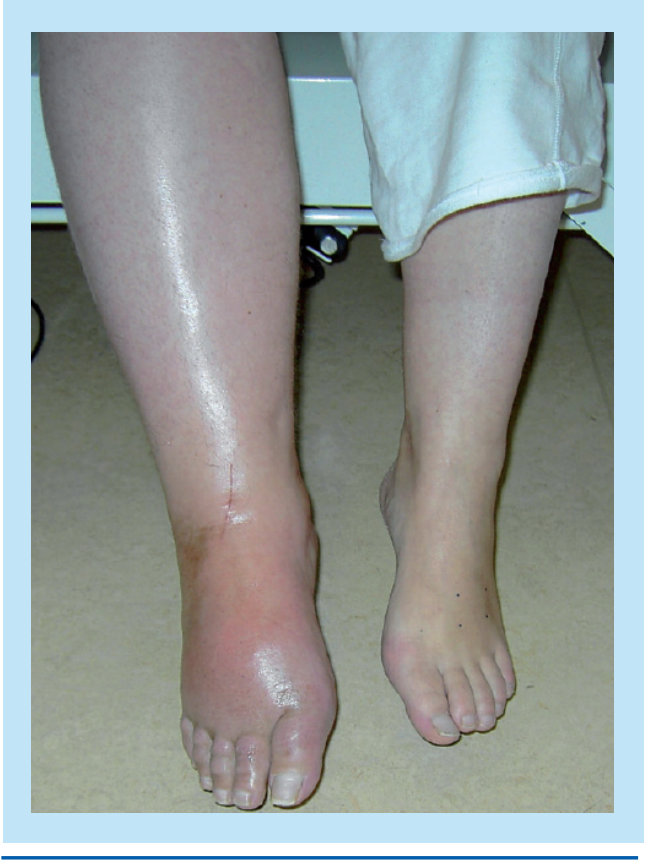

Figure 1. Acute complex regional pain syndrome with hyperemia, swelling and glossy skin.

Reproduced from [6] with permission from Elsevier.

with chronic (1-18 years) CRPS [43]. This study was prompted by patient reports of problems with word and number order, both written and verbal. Standardized clinical parietal function tests provided objective evidence of finger agnosia, stereognosis, dysgraphesthesia, conduction aphasia, right/left disorientation and agraphia in a cohort of 22 CRPS patients. The extent and degree of allodynia exhibited in a patient strongly correlated with the number of failed parietal tests; in other words, those with the more severe allodynia exhibited more aberrant parietal function. The findings of this study corroborate well with previous clinical and imaging studies

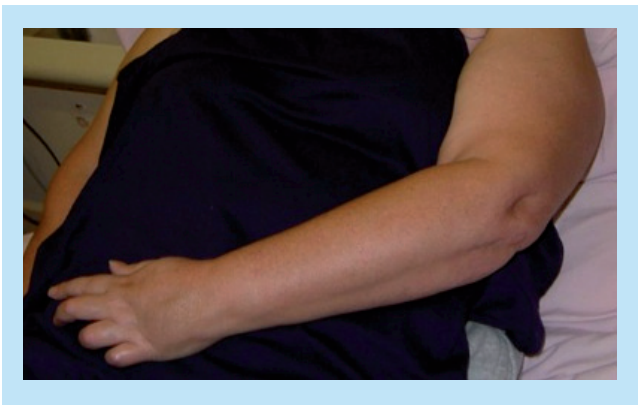

Figure 2. Complex regional pain syndrome in the persistent, chronic form. demonstrating disturbances in parietal cortex function in those with chronic CRPS [27,28,44-48].

As the parietal cortex is important for the assimilation of sensory and motor information to determine the level of perceived threat to the body, it is not surprising that those with CRPS present with high levels of anxiety and an overriding fear of touch to their affected limb. This fear-related response will be reflected by changes in autonomic regulation, and therefore autonomic pathway activity [49]. It has recently been observed that visual stimuli can also impact on autonomic function in those with chronic CRPS [50]. This study was prompted by clinical reports from patients that their vision appeared to be affected by their CRPS, although ophthalmological investigations failed to identify objective pathology. Using laser Doppler flowmetry, an asymmetrical pattern of response was identified (with significant variation in autonomic response between the affected and contralateral limbs) when those with CRPS viewed a Necker cube. A Necker cube is a bistable $3 \mathrm{D}$ object that appears to tilt in two different directions, depending on the viewer's mental vantage point (Figure 3). Processing this visual illusion is known to employ the dorsal, rather than the ventral, stream of the visual pathway [51]. This evolutionary-older pathway involves processing within the parietal lobe and visual areas, and is thought to be concerned with orienting oneself to an object and its location in extrapersonal space. Of the total cohort of patients $(n=30), 33.5 \%$ had asymmetric vasomotor responses when viewing the Necker cube, and all of the participants experienced increased pain as they looked at the image. All age- and gender-matched healthy controls in this study demonstrated a normal homologous symmetrical pattern of response and there were no reports of pain. This study provides direct evidence for the close relationship between pain, sensory processing and autonomic function, and builds on previous work that also demonstrated the generation of new sensory perceptions, including pain, when patients with chronic CRPS viewed a Necker cube [52].

The breadth and depth of signs and symptoms in chronic CRPS are only just starting to unravel, but evidence suggests there may be widespread systemic consequences of living with this condition for a protracted period of time [53]. Furthermore, symptoms may spread to affect other limbs and this commonly occurs in 
an ipsilateral or contralateral pattern and rarely occurs diagonally [54]. Spreading of symptoms to one or more limbs is commonly associated with a younger age at condition onset and a higher incidence of movement disorders [54]. 'Contiguous spread,' the slow but significant spread of symptoms in the limb originally affected, is most commonly observed [55].

The individual with chronic CRPS presents with a highly complex clinical picture, which requires time and sensitivity on the part of the clinician to fully comprehend. Commonly, the healthcare setting is 'time poor', and this patient is frequently taking a large number of pharmacological agents with side effects that may add further complications to an already unclear picture. In addition, the patient may have previously repeated their medical history to multiple healthcare practitioners and may be concerned that their ever-increasing list of problems may be interpreted as psychosomatic in origin, thus raising their anxiety levels. This combination of factors can result in a suboptimal starting point for the design of a therapeutic care pathway, hence the recommendation is to identify the condition early and start treatment promptly with the aim of avoiding long-term problems [1-3]. However, if CRPS is recognized early, can we really prevent it from progressing to this chronic form?

Which rehabilitation strategies should be implemented once CRPS is diagnosed?

Ideally, if CRPS were suspected, a prophylactic intervention would be delivered to reduce the requirement for rehabilitation strategies. Vitamin $\mathrm{C}$ has been shown to provide some protective benefit if taken at 500- or 1500-mg daily doses for 50 days immediately post wrist fracture [56,57]. To date, this is the only intervention that has been identified that may reduce the risk of CRPS post trauma and as it is an innocuous intervention, it is a low-risk option that may provide some protection. The additional advantage of Vitamin $\mathrm{C}$ is that it can be commenced before a diagnosis of CRPS has been confirmed [56,57]. As CRPS is a diagnosis of exclusion - that is, there is no other diagnosis that better explains the signs and symptoms [23], it can be particularly challenging to determine when pain and edema from trauma has progressed to the signs and symptoms of CRPS. The Atkins [58] and Veldman criteria [20], which predated the current Budapest criteria [23], were developed within an orthopedic setting.

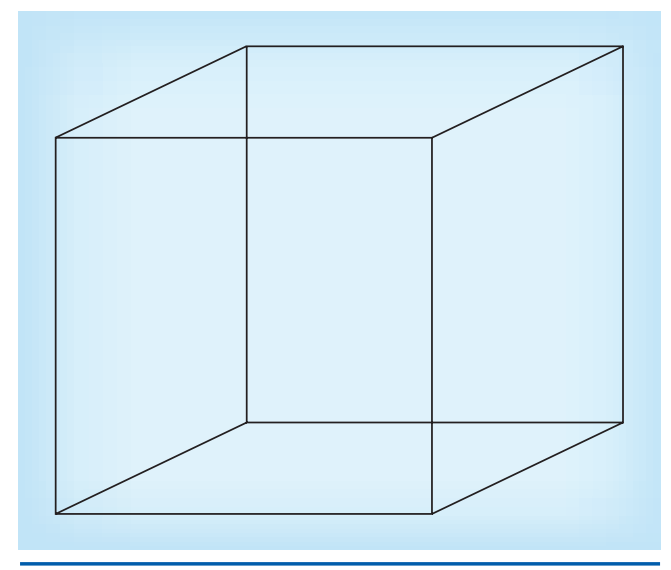

Figure 3. A Necker cube. The cube can be viewed in two different orientations depending on the viewer's perspective.

However, comparison of the Atkins criteria with more recent diagnostic criteria suggests there are no gross differences, just a slight variation in the assessment of pain [59]. Therefore, current criteria should be reliable for a post-fracture cohort.

Once CRPS has been diagnosed, a multidisciplinary approach is recommended [1-3], with current UK therapeutic guidelines suggesting this is delivered under four 'pillars' of care (education, pain relief, physical rehabilitation and psychological intervention) [3]. The aim of medication at this stage is to facilitate engagement with, and movement of, the CRPS affected limb. Psychological support and a clinical team trusted by the patient can further enable the patient to achieve this. The UK guidance extends the current International Association for the Study of Pain algorithm of three pathways of care (psychological treatment, rehabilitation pathway and interventional pain management) with the fourth pillar of education. Evidence suggests that patients are keen to be well informed about their condition from a reliable source [60]. Those with chronic CRPS have described how increasing their levels of understanding of the condition provides reassurance that they are not alone and can help to normalize what are often unsettling CRPS symptoms [60].

In recent years, the pillar of physical rehabilitation has developed considerably. A number of innovative therapies have emerged that have been inspired by imaging evidence of a highly plastic, and therefore potentially modifiable, CNS [61]. In particular, the evidence of a positive correlation between the degree of perceived 

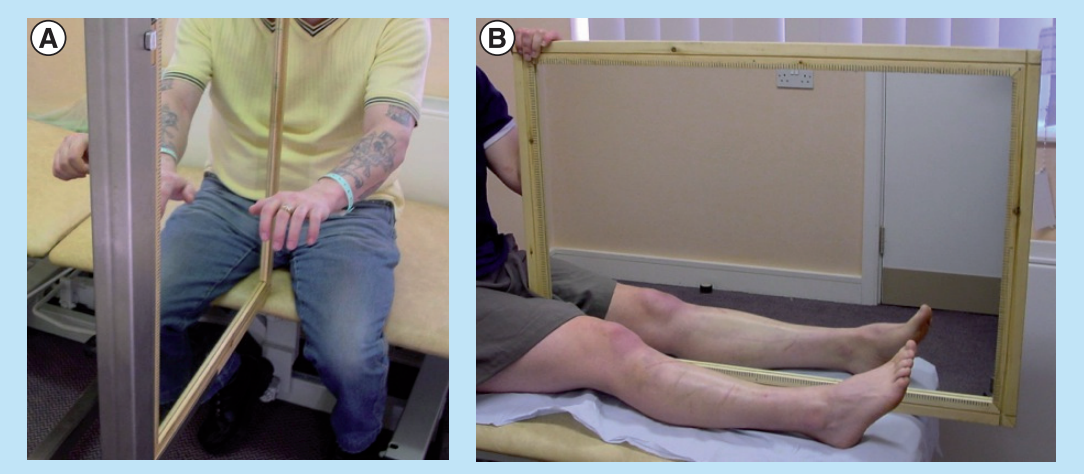

Figure 4. Mirror visual feedback for the upper or lower limb. The subject has their complex regional pain syndrome-affected (A) upper or (B) lower limb hidden from view behind the mirror while they view the reflected image of their unaffected limb. (B) Reprinted from [67] with permission from Oxford University Press. without the previous two stages of GMIP, and has been demonstrated to provide analgesic benefit, improve function and reverse thermal irregularities in those with early [67] and chronic CRPS [68]. Unlike GMIP, there is no definitive guidance or supporting evidence on the optimum frequency, duration of treatment sessions or recommended trial period for MVF. Treatment regimes tend to be devised between the patient and their therapist, informed by severity of symptoms, tolerance of the device and practical limitations [69]. Much work is still required to define a therapeutic 'dose' for MVF.

Physical rehabilitation is often difficult to initiate in those with CRPS due to the high levels of pain that movement commonly exacerbates. However, graded exposure therapy, a very recent innovation in the specialty of CRPS, encourages patients to progressively increase activities in a graded manner despite the pain [70,71], and may concurrently include the reduction, and eventually cessation, of analgesic medication [71]. The two studies conducted to date both used a singlecase design methodology and have demonstrated impressive results, with patients reporting dramatic reductions in pain intensity, pain-related fear, and improvements in function and muscle strength [70,71]. Intriguingly, in the most recent study by van de Meent and colleagues, only $18 \%$ of the total cohort $(n=20)$ had a reduction in kinesiophobia, which suggests that regular rehearsal of moving in the presence of pain does not automatically aid habituation [71]. This is a surprising finding and it will be interesting to see how this intervention develops when more data are available from larger trials of a longer duration. Evidence to date suggests this could be a promising new approach for CRPS rehabilitation.

When to implement rehabilitation?

As stated above, all current guidance on the treatment of CRPS promotes early diagnosis and intervention to optimize patient outcome [1-3]. However, this guidance, in terms of when to intervene, is based on expert clinical opinion and there are no definitive studies to inform the timing or sequence of interventions across the total therapeutic spectrum. With the majority of CRPS patients exhibiting only transient symptoms, and the lack of prognostic markers for those who will progress to the chronic form, the clinician walks a difficult line between 'watch and wait' and 'intervene aggressively and early'. As chronic CRPS has such devastating 


\section{Box 1. Limitations of review.}

- This review is focused on recent advances in rehabilitation strategies for complex regional pain syndrome (CRPS) in the clinical setting. It is not a comprehensive review of all potential interventional procedures for CRPS.

- The review is intended for those working outside the specialist field of CRPS, where a case of CRPS may be an infrequent event in their clinical practice.

- Profession-specific guidance can be found in the cited guidance documents.

consequences on the individual, and is resource intensive for health and social care, clinical guidelines currently recommend close observation of patients in the early stages of the condition, with rapid referral to specialist care if the patient is failing to progress or symptoms are worsening [3].

Much research is still required to determine the temporal aspects of CRPS care. Future work should include economic as well as health evaluations to ensure potentially expensive specialist resources are used in a timely manner to optimize patient outcome.

For a list of the limitations of this review, please see Box 1.

\section{Conclusion \& future perspective}

This article has considered the current challenges of delivering an evidence-based rehabilitation program for those with CRPS, but how are these challenges best addressed in the future?

Rare conditions, such as CRPS, need large networked consortia to generate the sample sizes required to make meaningful progress. The Netherlands-based TREND consortium have already demonstrated the efficacy of this approach [101]. Led by van Hilten, this national consortium worked with international collaborators to generate a vast body of research over an 8-year period. Their outputs significantly advanced our knowledge of the mechanisms and treatments of CRPS, and established a template for future research consortia.

\section{References}

Papers of special note have been highlighted as:

- of interest

1 Harden RN, Swan M, King A, Costa B, Barthel J. Treatment of complex regional pain syndrome. Functional restoration. Clin. J. Pain 22, 420-424 (2006).

2 Stanton-Hicks M, Burton AW, Bruehl S et al. An updated interdisciplinary clinical pathway for CRPS: report of an expert panel.

Pain Prac. 2, 1-16 (2002)

3 Goebel A, Barker CH, Turner-Stokes L et al. Complex Regional Pain Syndrome in Adults:

Many countries now have well-established national registers for CRPS and it is essential that these resources are linked on an international basis to maximize our research potential. The American patient charity (Reflex Sympathetic Dystrophy Syndrome Association) have recognized the advantages of this networked approach and currently fund a nascent international consortia that aims to define recovery from CRPS [102]. This type of collaborative working will ultimately help us to define biomarkers for CRPS that will ideally enable us to identify those at greatest risk of developing the chronic form. In the meantime, over the next 5-10 years we should be able to tailor interventions to specific phenotypes and define a more evidence-based pathway of care, dependent on presenting signs and symptoms. Much work is required to move toward this stage and it is essential to involve patients within this work; working with patients as experts in the field will ensure our research remains focused on what matters most to them.

\section{Financial \& competing interests disclosure}

CS McCabe is funded by an NIHR Career Development Fellowship and receives research funds from RSDSA for an international collaborative project. The author has no other relevant affiliations or financial involvement with any organization or entity with a financial interest in or financial conflict with the subject matter or materials discussed in the manuscript apart from those disclosed.

No writing assistance was utilized in the production of this manuscript.

UK Guidelines for Diagnosis, Referral and Management in Primary and Secondary Care. Royal College of Physicians, London, UK (2012).

- These recently published national guidelines provide detailed recommendations on the care of complex regional pain syndrome from early to chronic forms. Profession-specific guidance is incorporated within the guidelines, as well as example patient information documents.

4 Quisel A, Gill JM, Witherell P. Complex regional pain syndrome underdiagnosed. J. Fam. Pract. 54(6), 524-532 (2005).
5 Allen G, Galer BS, Schwartz L. Epidemiology of complex regional pain syndrome: a retrospective chart review of 134 patients. Pain 80, 539-544 (1999).

6 Marinus J, Moseley GL, Birklein F et al. Clinical features and pathophysiology of complex regional pain syndrome. Lancet Neurol. 10(7), 637-648 (2011).

- Provides an excellent comprehensive review of the mechanisms of complex regional pain syndrome and how these underlying mechanisms relate to presenting signs and symptoms. 
7 Jänig W, Baron R. Complex regional pain syndrome: mystery explained? Lancet Neurol. 2, 687-697 (2003).

8 Field J, Warwick D, Bannister GC. Features of algodystrophy ten years after Colles' fracture. J. Hand Surg. Br. 17(3), 318-320 (1992).

9 Geertzen JHB, Dijkstra PU, van-Sonderon EL et al. Relationship between impairment, disability and handicap in reflex sympathetic dystrophy patients; a long-term follow-up study. Clin. Rehabil. 12, 402-412 (1998).

10 Schasfoort FC, Bussmann JB, Stam HJ. Impairments and activity limitations in subjects with chronic upper-limb complex regional pain syndrome type I. Arch. Phys. Med. Rehabil. 85(4), 557-566 (2004).

11 Dijkstra PU, Geertzen JHB. Reliability of assessment of motor function and swelling in patients with chronic CRPS-I of the upper extremity. In: Complex Regional Pain Syndrome. Harden RN, Baron R, Jänig W (Eds). IASP Press, Seattle, WA, USA, 249-259 (2001).

12 Sandroni P, Benrud-Larson LM, McClelland RL, Low PA. Complex regional pain syndrome type I: incidence and prevalence in Olmsted county, a populationbased study. Pain 103(1-2), 199-207 (2003).

13 de Mos M, de Bruijn AGJ, Huygen FJPM, Dieleman JP, Stricker BHC, Sturkenboom MCJM. The incidence of complex regional pain syndrome: a population-based study. Pain 129(1-2), 12-20 (2007).

14 Craig P, Dieppe P, Macintyre S, Michie S, Nazareth I, Petticrew M. Developing and evaluating complex interventions: the new Medical Research Council guidance. BMJ 337, 979-983 (2008).

15 Beerthuizen A, Stronks DL, Huygen FJPM, Passchier J, Klein J, Spijker AV. The association between psychological factors and the development of complex regional pain syndrome type 1 (CRPS1) - a prospective multicenter study. Eur. J. Pain 15(9), 971-975 (2011).

16 de Mos M, Huygen FJPM, Dieleman JP, Koopman JSHA, Stricker BHC, Sturkenboom MCJM. Medical history and the onset of complex regional pain syndrome (CRPS). Pain 139, 458-466 (2008).

17 Field J, Protheroe DL, Atkins RM. Algodystrophy after Colles fractures is associated with secondary tightness of casts. J. Bone Joint Surg. Br. 76(6), 901-905 (1994).

18 de Mos M, Huygen FJPM, Stricker BHC, Dieleman JP, Sturkenboom MCJM.
The association between ACE inhibitors and the complex regional pain syndrome: suggestions for a neuro-inflammatory pathogenesis of CRPS. Pain 142, 218-224 (2009).

19 de Rooij AM, de Mos M, Van Hilten JJ et al. Increased risk of complex regional pain syndrome in siblings of patients? J. Pain 10 (12), 1250-1255 (2009).

20 Veldman PJHM, Reynen HM, Arntz IE, Goris RJA. Signs and symptoms of reflex sympathetic dystrophy: prospective study of 829 patients. Lancet 342 (8878), 1012-1016 (1993).

21 Stanton-Hicks M, Jänig W, Hassenbusch S, Haddos JD, Boas R, Wilson P. Reflex sympathetic dystrophy: changing concepts and taxonomy. Pain 63, 127-133 (1995).

22 Baron R, Fields HL, Jänig W, Kitt C, Levine JD. National Institutes of Health Workshop: reflex sympathetic dystrophy/ complex regional pain syndromes - state-ofthe-science. Anesth. Analg. 95, 1812-1816 (2002).

23 Harden RN, Bruehl S, Perez RS et al. Validation of proposed diagnostic criteria (the 'Budapest Criteria') for Complex Regional Pain Syndrome. Pain 150(2), 268-274 (2010).

- Presents the current complex regional pain syndrome diagnostic criteria and provides detailed information on how these criteria were developed and validated.

24 Jensen TS, Baron R, Haanpaa M et al. A new definition of neuropathic pain. Pain 152 (10), 2204-2205 (2011).

25 McCabe CS, Blake DR. An embarrassment of pain perceptions? Toward an understanding of and explanation for the clinical presentation of CRPS type 1. Rheumatology 47, 1612-1616 (2008).

26 Van Hilten JJ, Blumberg H, Schwartzman RJ. Factor IV: movement disorders and dystrophy - pathophysiology and measurement. In: CRPS: Current Diagnosis and Therapy. Wilson PR, Stanton-Hicks M, Harden RN (Eds). IASP Press, Seattle, WA, USA, 119-137 (2005).

27 Moseley L. Distorted body image in complex regional pain syndrome. Neurology 65, 773 (2005).

28 Lewis JS, Kersten P, McCabe CS, McPherson KM, Blake DR. Body perception disturbance: a contribution to pain in complex regional pain syndrome. Pain 133 , 111-119 (2007).

29 Peltz E, Seifert F, Lanz S, Muller R, Maihofner C. Impaired hand size estimation in CRPS. J. Pain 12, 1095-1101 (2011).
30 McCabe CS, Haigh RC, Halligan PW, Blake DR. Referred sensations in complex regional pain syndrome Type 1. Rheumatology 42, 1067-1073 (2003).

31 Maihöfner C, Neundörfer B, Birklein F, Handwerker HO. Mislocalization of tactile stimulation in patients with complex regional pain syndrome. J. Neurol. 253, 772-779 (2006).

32 Flor H, Nikolajsen L, Jensen TS. Phantom limb pain: a case of maladaptive CNS plasticity? Nat. Rev. Neurosci. 7, 873-881 (2006).

33 Maihofner C, Handwerker HO, Neundorfer B, Birklein F. Patterns of cortical reorganization in complex regional pain syndrome. Neurology 61, 1707-1715 (2003).

34 Maihöfner C, Baron R, DeCol R et al. The motor system shows adaptive changes in complex regional pain syndrome. Brain 130 , 2671-2687 (2007).

35 Maihöfner C, Handwerker H, Neundörfer B, Birklein F. Cortical reorganisation during recovery from complex regional pain syndrome. Neurology 63, 693-701 (2004).

36 Pleger B, Tegenthoff M, Ragert P et al. Sensorimotor retuning in complex regional pain syndrome parallels pain reduction. Ann. Neurol. 57(3), 425-429 (2005).

37 Munts AG, Mugge W, Meurs TS et al. Fixed dystonia in complex regional pain syndrome: a descriptive and computational modelling approach. BMC Neurol. 11, 53 (2011).

38 Van Rijn MA, Marinus J, Putter H, Van Hilten JJ. Onset and progression of dystonia in Complex Regional Pain Syndrome. Pain 130(3), 287-293 (2007).

39 Muntts AG, van Rijn MA, Geraedts EJ, van Hilten JJ, van Dijk JG, Marinus J. Thermal hypesthesia in patients with complex regional pain syndrome related dystonia. J. Neural Transm. 118, 599-603 (2011).

40 Maier C, Baron R, Tolle TR et al. Quantitative sensory testing in the German Research Network on Neuropathic Pain (DFNS): somatosensory abnormalities in 1236 patients with different neuropathic pain syndromes. Pain 150, 439-450 (2010).

41 Oaklander AL, Rissmiller JG, Gelman LB et al. Evidence of focal small-fiber axonal degeneration in complex regional pain syndrome-I (reflex sympathetic dystrophy). Pain 120, 235-243 (2006).

42 Drummond PD. Sensory disturbances in complex regional pain syndrome: clinical observations, autonomic interactions, and possible mechanisms. Pain Med. 11, 1257-1266 (2010). 
43 Cohen $\mathrm{H}, \mathrm{McC}$ abe C, Harris N et al. Clinical evidence of parietal cortex dysfunction and correlation with extent of allodynia in complex regional pain syndrome (CRPS) type 1. Eur. J. Pain doi:10.1002/j.1532-2149. 2012.00213.x (2012) (Epub ahead of print).

44 Forderreuther S, Sailer U, Straube A. Impaired self-perception of the hand in complex regional pain syndrome (CRPS). Pain 110, 756-761 (2004).

45 Robinson G, Cohen H, Goebel A. A case of complex regional pain syndrome with agnosia for object orientation. Pain 152(7), 1674-1681 (2011).

46 Schwoebel J, Friedman R, Duda N, Coslett H. Pain and the body schema; evidence for peripheral effects on mental representations of movement. Brain 124, 2098-2104 (2001).

47 Shiraishi S, Kobayashi H, Nihashi T et al. Cerebral glucose metabolism change in patients with complex regional pain syndrome: a PET study. Radiat. Med. 24, 335-344 (2006).

48 Vartiainen NV, Kirveskari E, Forss N. Central processing of tactile and nociceptive stimuli in complex regional pain syndrome. Clin. Neurophysiol. 119, 2380-2388 (2008).

49 Jänig W, Baron R. Is CRPS I a neuropathic pain syndrome? Pain 120, 227-229 (2006).

50 Cohen H, Hall J, Harris N, McCabe C, Jänig W, Blake D. Enhanced pain and autonomic responses to ambiguous visual stimuli in chronic complex regional pain syndrome (CRPS) type I. Eur. J. Pain 16(2), 182-195 (2012).

51 Schoth F, Waberski TD, Krings T, Gobbele R, Buchner H. Cerebral processing of spontaneous reversals of the rotating Necker cube. Neuroreport 18(13), 1335-1338 (2007).

52 Hall J, Harrison S, Harris N, McCabe C, Blake D. Pain and other symptoms of CRPS can be increased by ambiguous visual stimuli - an exploratory study. Eur. J. Pain 15, 17-22 (2011).

53 Schwartzman RJ. Systemic complications of complex regional pain syndrome. neuroscience $\&$ medicine. Neurosci. Med. 3(3), 225-242 (2012).
54 van Rijn MA, Marinus J, Putter $\mathrm{H}$ et al. Spreading of complex regional pain syndrome: not a random process. J. Neural Transm. 118(9), 1301-1309 (2011).

55 Maleki J, LeBel AA, Bennett GJ, Schwartzman RJ. Patterns of spread in complex regional pain syndrome, type I (reflex sympathetic dystrophy). Pain 88, 259-266 (2000).

56 Zollinger PE, Tuinebreijer WE, Kreis RW, Breederveld RS. Effect of vitamin C on frequency of reflex sympathetic dystrophy in wrist fractures: a randomised trial. Lancet 354(9195), 2025-2028 (1999).

57 Zollinger PE, Tuinebreijer WE, Breederveld RS et al. Can vitamin C prevent complex regional pain syndrome in patients with wrist fractures? A randomized, controlled, multicenter dose-response study. J. Bone Joint Surg. Am. 89, 1424-1431 (2007).

58 Atkins RM, Duckworth T, Kanis JA. Features of algodystrophy after Colles' fracture. J. Bone Joint Surg. Br. 72(1), 105-110 (1990).

59 Thomson McBride AR, Barnett AJ, Livingstone JA, Atkins RM. Complex regional pain syndrome (type 1 ): a comparison of 2 diagnostic criteria methods. Clin. J. Pain 24(7), 637-640 (2008).

60 Rodham K, McCabe C, Pilkington M, Regan L. Coping with chronic complex regional pain syndrome: advice for patients from patients. Chronic Illn. doi:10.1177/1742395312450178 (2012) (Epub ahead of print).

61 Bailey J, Nelson S, Lewis J, McCabe C. Imaging and clinical evidence of sensorimotor problems in CRPS: utilizing novel treatment approaches. J. Immune Neuropharmacol. doi:10.1007/s11481-012-9405-9 (2012) (Epub ahead of print).

62 Moseley GL. Graded motor imagery is effective for long-standing complex regional pain syndrome: a randomised controlled trial. Pain 108, 192-198 (2004).

63 Daly AE, Bialocerkowski AE. Does evidence support physiotherapy management of adult complex regional pain syndrome type one? A systematic review. Eur. J. Pain 13(4), 339-353 (2009).
64 Moseley GL. Is successful rehabilitation of complex regional pain syndrome due to sustained attention to the affected limb? A randomised clinical trial. Pain 114, 54-61 (2005).

65 Moseley GL. Graded motor imagery for pathologic pain: a randomized controlled trial. Neurology 67, 2129-2134 (2006).

66 Johnson S, Hall J, Barnett $S$ et al. Using graded motor imagery for complex regional pain syndrome in clinical practice: failure to improve pain. Eur. J. Pain 16(4), 550-561 (2011).

67 McCabe CS, Haigh RC, Ring EF, Halligan PW, Wall PD, Blake DR.

A controlled pilot study of the utility of mirror visual feedback in the treatment of complex regional pain syndrome (type 1). Rheumatology 42(1), 97-101 (2003).

68 Cacchio A, De BE, Necozione S, di Orio F, Santilli V. Mirror therapy for chronic complex regional pain syndrome type 1 and stroke. N. Engl. J. Med. 361(6), 634-636 (2009).

69 McCabe CS. Mirror visual feedback; a practical approach. J. Hand Ther. 24(2), 170-178 (2011).

70 de Jong JR, Vlaeyen JWS, Onghena P, Cuypersf C, den Hollanderg M, Ruijgroka J. Reduction of pain-related fear in complex regional pain syndrome type I: the application of graded exposure in vivo. Pain 116, 264-275 (2005).

71 van de Meent H, Oerlemans M, Bruggeman A et al. Safety of 'pain exposure' physical therapy in patients with complex regional pain syndrome type 1. Pain 152(6), 1431-1438 (2011).

72 Harden RN, Bruehl S, Stanton-Hicks M et al. Proposed new diagnostic criteria for complex regional pain syndrome. Pain Med. 8 , 326-331 (2007).

\section{- Websites}

101 TREND. www.trendconsortium.nl

102 Reflex Sympathetic Dystrophy Syndrome Association. www.rsdsa.org 